\title{
Constituents of Pine Heartwood
}

\author{
XI. The Heartwood of Pinus radiata D.Don
}

\author{
G ÖSTA LINDSTEDT
}

Organisk-kemiska Institutionen, Kungl. Tekniska Högskolan, Stockholm, Sweden

\begin{abstract}
Wonterey pine, Pinus radiata D. Don, is a pine of the Diploxylon section Igrowing on the Pacific coast of North America. The heartwood used at the present investigation came from a cultivated tree grown at Farnham,
\end{abstract} Surrey, England.

The extractions were carried out according to the general scheme given in Part IX ${ }^{1}$. The ether extract ( $8 \%$ of air-dry heartwood) crystallised partly. A phenolic fraction (1\% of the ether extract) could be prepared from it. This was not investigated any further.

A small quantity of $l$-arabinose was isolated from the aqueous residue after the evaporation of the acetone from the acetone extract. This is in good agreement with an observation by Erdtman ${ }^{2}$, who found $l$-arabinose along with the 'membrane substances' of $P$. sylvestris.

The sodium carbonate fraction of the acetone extract contained a precipitate, which partly consisted of the sodium salt of pinobanksin. The pinobanksin crystallised from toluene in large thick needles, m.p. 176-178 *, containing crystal toluene. After drying at $115^{\circ}$ the m. p. was almost unchanged, $177-178^{\circ} .[\alpha]_{\mathrm{D}}^{20}+14.5^{\circ}$ (in methanol). The loss in weight during the drying corresponds to half a mole of crystal toluene for each mole of pinobanksin.

Pinocembrin was obtained from the soluble part of the sodium carbonate extract and from the $0.2 \%$ sodium hydroxide extract. M. p. $193-194^{\circ}$; $[\alpha]_{\mathrm{D}}^{20}-57^{\circ}$. This specific rotation is in relatively good agreement with that found for pinocembrin from $P$. montana ${ }^{1}$ and $P$. contorta ${ }^{3}$.

The $4 \%$ sodium hydroxide extract yielded pinosylvin monomethyl ether.

* All melting points uncorrected. 
The following fractions were isolated from $2.5 \mathrm{~kg}$ of air-dry heartwood.

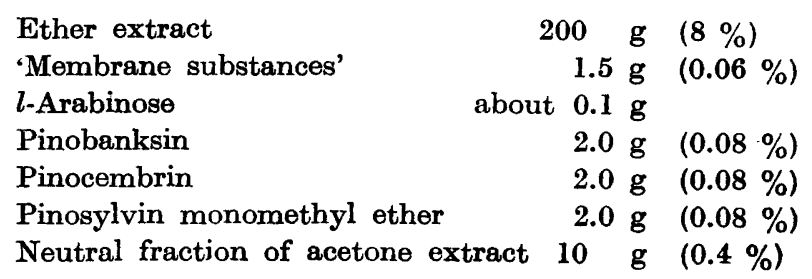

The specimen of $P$. radiata investigated here had a relatively small amount of phenolic substances in the heartwood. Pinosylvin has not been isolated, but of course there may be small quantities of that substance in the noncrystalline resins which always accompany the crystalline substances.

\section{EXPERIMENTAL}

The wood sample came from Forest Research Station, Alice Holt Lodge, Farnham, Surrey, England.

$2.5 \mathrm{~kg}$ of heartwood were extracted first with ether and then with acetone in the same way as described for Pinus montana ${ }^{1}$.

After the ether extract had been evaporated, a dark brown syrup remained, which crystallised to a great extent in a few weeks. Yield, $200 \mathrm{~g}$. $6.02 \mathrm{~g}$ of the ether extract were treated with $120 \mathrm{ml}$ of light petroleum. A brownish-yellow precipitate was filtered off, washed and dried, yielding $0.55 \mathrm{~g}$. This was boiled with $150 \mathrm{ml}$ of water, and the water solution filtered and cooled. It was then extracted with ether, and the ether solution dried over sodium sulphate and evaporated to dryness, when $0.06 \mathrm{~g}$ of a brown resinous substance was obtained. It gave a brownish-violet colour with ferric chloride in alcoholic solution.

The acetone extract was evaporated. The residue consisted of a small volume of water and a dark brown resin. The water $(=\mathrm{W})$ was separated from the resin by decantation. It reduced Fehling's solution and had a positive rotation. The resin was treated with $600 \mathrm{ml}$ of ether, and the undissolved sticky brown "membrane substances" filtered off. Yield, $1.5 \mathrm{~g}$. The filtrate was then shaken with $100 \mathrm{ml}$ of water, which was combined with W.

The ether solution was next shaken with saturated sodium bicarbonate solution $(3 \times 500 \mathrm{ml}$, extract $=\mathrm{B})$ and with saturated sodium carbonate $(4 \times 200 \mathrm{ml})$. From the last-mentioned extract a brown precipitate was separated $\left(=\mathrm{C}_{1}\right)$. Aqueous filtrate $=\mathrm{C}_{2}$.

After the carbonate extraction, the ether solution was diluted to $800 \mathrm{ml}$ and first shaken with $0.2 \%$ sodium hydroxide $\left(3 \times 250 \mathrm{ml}\right.$, extract $\left.=\mathrm{H}_{1}\right)$ and then with $4 \%$ sodium hydroxide $\left(250+150 \mathrm{ml}\right.$, extract $\left.=\mathrm{H}_{2}\right)$. The residue was dried over sodium sulphate and evaporated. The remaining reddish-brown oil $(10 \mathrm{~g})$ had a strong fluorescence and a turpentine-like odour.

$W$ was concentrated in vacuo to a brown syrup. The syrup was extracted with hot ethanol, the extract evaporated to dryness and the residue recrystallised twice from ethanol. A small amount of a white crystalline powder, melting at $155-158^{\circ}$ was obtained 
(about $100 \mathrm{mg}$ ). This product gave a precipitate with $p$-bromophenylhydrazine in acetic acid solution and a strong pentose colour reaction with phloroglucinol and hydrochloric acid. When mixed with an equal amount of $l$-arabinose, its melting point was unchanged. $[\alpha]_{\mathrm{D}}^{20}+105^{\circ} \pm 1^{\circ}$ (equilibrium rotation in $2.4 \%$ aqueous solution). Reported for $l$-arabinose: $+105.5^{\circ}$.

$B$, when acidified, formed a brown sticky precipitate (about $1 \mathrm{~g}$ ), which was not investigated any further.

$C_{1}$ was stirred with dilute sulphuric acid, washed with water and dried in the air. This treatment yielded a brown solid $(12.9 \mathrm{~g})$. It could not be recrystallised directly, but when extracted with ether for four hours in a Soxhlet apparatus, most of it dissolved. When evaporated, the ether extract yielded a crystalline cake, melting gradually at $145-165^{\circ}$. Recrystallisation from toluene also yielded an impure product, which was dissolved in ether and shaken with saturated sodium carbonate. A crystalline yellow precipitate was formed in the aqueous phase. It was separated from the solution and acidified. After four recrystallisations from toluene, pure pinobanksin $(2.1 \mathrm{~g})$ was obtained, melting at $176-178^{\circ}$. When dried at $115^{\circ}$, the crystals lost $0.3 \mathrm{~g}$ in weight and melted at $177-178^{\circ} .[a]_{D_{i}}^{20}+14.5^{\circ} \pm 0.5^{\circ}$ (methanol, $c=6.0$ ).

The toluene mother liquors were evaporated and the residues recrystallised from $50 \%$ acetic acid. Crude pinocembrin was obtained and combined with pinocembrin found in the $\mathrm{C}_{2}$ fraction. After filtering through aluminium oxide in ether solution and recrystallisation from $40 \%$ acetic acid, $1.8 \mathrm{~g}$ of pure pinocembrin (m. p. $193-194^{\circ}$ ) could be separated. The total yield of pinocembrin from the $\mathrm{C}$ and $\mathrm{H}$ fractions was 2.0 g. $[a]_{\mathrm{D}}^{20}-57^{\circ} \pm 1^{\circ}$ (methanol, $c=2.3$ ).

The $C_{2}$ fraction was acidified and the resulting brown precipitate separated from the solution. It was extracted with ether like $C_{1}$, but the ether extract could not be crystallised from organic solvents. Several extractions with boiling water yielded crystalline colourless precipitates on cooling, the first melting about $140^{\circ}$ and the last about $190^{\circ}$. From the first precipitates $0.15 \mathrm{~g}$ of pinobanksin (m. p. $177-178^{\circ}$ ) was isolated by precipitation as sodium salt and recrystallisation from toluene. The last extracts consisted of crude pinocembrin and were combined with the pinocembrin found in the $\mathbf{C}_{1}$ fraction.

$H_{1}$ was acidified and extracted with ether, and the ether extract washed with a small volume of saturated sodium carbonate solution and then concentrated to a yellow oil. From this a small quantity of pinocembrin could be isolated after water extraction and recrystallisation from dilute acetic acid. M. p. 195-197.

$H_{2}$ was acidified, extracted with ether and the ether evaporated to dryness. A brown, semi-crystalline mass was obtained, which was distilled in vacuo and then recrystallised from $50 \%$ acetic acid. $2.0 \mathrm{~g}$ of pinosylvin monomethyl ether, m. p. $119-121^{\circ}$, were obtained.

\section{SUMMARY}

Pinobanksin, pinocembrin, pinosylvin monomethyl ether and a small quantity of $l$-arabinose have been isolated from the heartwood of Pinus radiata D. Don.

The author is indebted to Mrs. B. Strömgren for skilful assistance during the experimental work, and to Mr. M. V. Laurie, Alice Holt Lodge, Farnham, Surrey, England, for 
the supply of the wood. The investigation was facilitated by a grant from Statens Tekniska Forskningsrad.

\section{REFERENCES}

1. Lindstedt, G. Acta Chem. Scand. 3 (1949) 755.

2. Erdtman, H. Svensk Papperstidn. 46 (1943) 226.

3. Lindstedt, G. Acta Chem. Scand. 3 (1949) 759.

Received June 22, 1949.

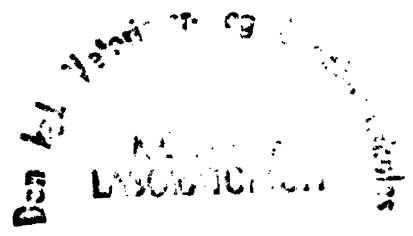

